\title{
O social para a saúde mental sob a contrarreforma neoliberal
}

\author{
The "social" in mental health under neoliberal counter-reform
}

\section{Rita CAVALCANTE*}

https://orcid.org/0000-0001-9918-7503

\section{Introdução}

$\mathrm{E}$ ste número da Revista Argumentum, dedicado às políticas de saúde mental no Brasil e no plano internacional: tendências e desafios, tem como título para o artigo disparador da Sessão Debate A gravidade do neoliberalismo radical pós $2008 e$ nossas estratégias de resistência.

Para este diálogo, o presente texto é escrito há quatro meses das medidas iniciadas de distanciamento social no Brasil, relativas ao enfrentamento da pandemia da COVID-19. Trata-se de um longo período para suportar o desgaste psicossomático relativo às restrições de socialização e sem perspectiva ainda de declínio da incidência da transmissão do coronavírus no País. Sem as medidas sanitárias e de biossegurança necessárias para a proteção à vida, expressão de um capitalismo em sua variante mais primitiva e neofascista, o resultado que se colhe é uma massa crescente de mortos e de trabalhadores desempregados, na informalidade, na intermitência e sob contratos precarizados, cujos empregos apresentam estes traços da uberização do mundo do trabalho (ANTUNES, 2018; 2020).

A pandemia apenas vem agravando a crise econômica transnacional com impactos presentes e de longo alcance à reprodução da vida e às relações de trabalho. Segundo as estimativas da Organização Internacional do Trabalho (OIT), elaboradas ainda em março de 2020, "[...] além das preocupações urgentes com a saúde das(os) trabalhadoras(es) e de suas famílias, o vírus e a crise econômica resultante da pandemia impactarão o mundo do trabalho em três dimensões principais [...]" (ORGANIZAÇÃO INTERNACIONAL DO TRABALHO, 2020, não paginado), a saber: aumento substancial no desemprego e subemprego; amplos ajustes em termos de redução de salários e horas de trabalho e grandes perdas de renda para as(os) trabalhadoras(es). Neste caso, a estimativa é que a perda de renda e, por consequência, de consumo, oscile entre 860 bilhões a 3,4 trilhões de dólares. A OIT alerta que o impacto será desigual entre os países

\footnotetext{
* Assistente Social. Doutora em Serviço Social pela Universidade Federal do Rio de Janeiro (UFRJ). Professora Associada da Escola de Serviço Social/UFRJ. E-mail: r.lima@ess.ufrj.br; copiar e redistribuir o material em qualquer suporte ou formato, bem como adaptar, transformar e criar a partir deste material para qualquer fim, mesmo que comercial. O licenciante não pode revogar estes direitos desde que você respeite os termos da licença.
} 
de maior e de baixa renda e que outros indicadores serão relevantes para conformar essa desproporcionalidade, como a condição prévia de saúde dos trabalhadores; a faixa etária, particularmente, o jovem e o idoso; as mulheres; os migrantes e, finalmente, os trabalhadores que já se encontravam em subemprego sem uma proteção trabalhista e social.

[...] mulheres, como resultado do extenso trabalho que realizam em setores mais afetados (principalmente serviços), ou por realizar trabalhos de linha de frente para lidar com a pandemia (por exemplo, enfermeiras). Segundo estimativas da OIT, $58,6 \%$ das mulheres que trabalham em todo o mundo o fazem no setor terciário, em comparação com $45,4 \%$ dos homens. As mulheres têm menos acesso aos serviços de proteção social e suportam uma carga de trabalho desproporcional na economia da cuidados, particularmente no caso de fechamento de escolas ou centros de assistência (ORGANIZAÇÃO INTERNACIONAL DO TRABALHO, 2020, não paginado).

No Brasil, Dantas (2020) sumaria que a situação é particularmente grave seja pela longa crise política em curso, mas especialmente pelo quadro de estagnação econômica que perdura há seis anos, com Produto Interno Bruto negativos, como os dos anos de 2015 e 2016 ou próximos a zero. Neste circuito, o autor infere que frente ao ajuste fiscal e as contrarreformas trabalhista e previdenciária recentes, os trabalhadores informais estão sendo "[...] mais diretamente penalizados com o desemprego e o desamparo. E não por coincidência, o país tem batido recordes de informalidade, como uma das consequências diretas da desregulamentação das relações trabalhistas" (DANTAS, 2020, p. 3).

O artigo A gravidade do neoliberalismo radical pós 2008 e nossas estratégias de resistência de autoria de Eduardo Mourão Vasconcelos, finalizado em 17 de março de 2020, portanto, antes da abertura da grave crise sanitária, mantém o mérito de desvelar mediações sobre essas tendências estruturais da ofensiva neoliberal em curso no plano transnacional e brasileiro. É um texto convidativo a qualquer leitor interessado a apreender a crise estrutural e conjuntural em curso e não somente aos interessados pela saúde mental.

Segundo Vasconcelos (2020), a problematização faculta reafirmar a necessidade de autocrítica da saúde mental, na medida em que a edificação de uma sociedade sem manicômios está condicionada a um projeto societário radicalmente democrático econômico e politicamente, que se encontra em profunda crise e ameaça os avanços conquistados nesta política de saúde. No entanto, Vasconcelos $(2012 ; 2016)$ já vinha advertindo os trabalhadores e os movimentos sociais da área da saúde mental sobre o significado dessa crise desde o início da década passada.

[...] o foco mais alongado nas questões sócio-culturais e particularmente psicossociais busca alertar nossos companheiros profissionais, gestores de políticas e ativistas destes campos, no sentido de estarem atentos às profundas consequências e novas demandas que as transformações econômicas, sociais e ambientais estão fazendo emergir em nossas áreas de atuação (VASCONCELOS, 2012, p. 151)

Esse alerta é substantivo para o processo da reforma psiquiátrica brasileira, na medida em que as estratégias de desinstitucionalização (ROTELLI; LEONARDIS; MAURI, 1990)

Argum., Vitória, v. 12, n. 2, p. 36-43, maio/ago. 2020. | ISSN 2176-9575 
requeriam a construção de um outro lugar social para a loucura (BIRMAN, 1992) e não apenas a ultrapassagem do manicômio, enquanto lócus do tratamento da doença mental, tomada como objeto da psiquiatria. A reforma não se limitou à reforma de serviços e tecnologias de cuidado, embora essa dimensão para o trabalho e para a formação em saúde mental também seja relevante. Como lembrou Rotelli, Leonardis e Mauri (1990, p. 90), "[...] o objeto sempre foi a 'existência-sofrimento dos pacientes e sua relação com o corpo social”. Para os autores italianos, a psiquiatria se constituiu como instituição dissociando seu "[...] objeto fictício - a doença - da existência global, complexa e concreta do paciente e do corpo da sociedade" (ROTELLI; LEONARDIS; MAURI, 1990, p. 90). Essa fratura, contudo, não é endógena à psiquiatria, mas remonta a própria constituição das Ciências Sociais e de outras áreas de conhecimento que estabeleceram autoridade sobre objetos recortados da realidade ou mais ao indivíduo biologia, psicologia, psicanálise etc. - ou mais à sociedade - economia, história, antropologia etc. Ora, estaria a saúde mental enquanto espaço teórico complexo e interprofissional imune àquela dissociação entre indivíduo e sociedade?

A reforma psiquiátrica propôs um processo de desinstitucionalização operado por múltiplos componentes, como o epistemológico, o legislativo, o cultural e os serviços, que fossem construídos através de "[...] estratégias e dispositivos políticos, sociais e culturais, e não apenas clínicos e terapêuticos” (AMARANTE; NUNES, 2018, p. 2170). Aqui, a saúde mental se convocou a tomar parte do campo da saúde coletiva onde a política e o social deixaram de ser adjetivos para se substantivar no pensamento social da saúde. Não se tratava mais da psicologia social, da psiquiatria social e tantas outras adjetivações do social, mas solo e uma determinação fundamental do processo saúde doença.

Retomar essa breve incursão após 30 anos do Sistema Único de Saúde nos parece ser precioso no debate com o artigo de Vasconcelos (2020), pois os fundamentos da orientação neoliberal já estavam sendo experimentados no mundo ao tempo da implantação desse sistema universal de saúde - no Chile com Augusto Pinochet (19741990), na Inglaterra com Margaret Thatcher (1979-1990) e nos Estados Unidos com Ronald Reagan (1981-1989). Não se tratava de políticas de governos particulares, mas de uma racionalidade neoliberal que invadiu as políticas de Estado, em resposta à requisição para a recomposição das taxas de lucro perdidas com a crise estrutural do capital iniciada nos anos de 1970 e agravada recentemente em 2008. Portanto, Vasconcelos (2020) examina esta crise, seus efeitos sobre a saúde mental, mas nos exorta para valorizar brechas fecundas para a gestação de uma nova sociabilidade, cujo espaço e tempo possam facultar um lugar social para a loucura.

A partir desse esforço, dialogamos com os pontos teóricos, históricos e políticos realçados por Vasconelos sobre neoliberalismo em curso no Brasil, dando ênfase ao caráter contrarreformista (DEMIER, 2017), antidemocrático e neoconservador (DARDOT; LAVAL, 2016), típico das democracias do tipo liberal e tardia constituída no Brasil.

Dotadas de um caráter hegemônico - isto é, combinando de forma equilibrada elementos de coerção e consenso -, tais democracias apresentam estruturas hermeticamente fechadas às pressões populares, preservando seus núcleos

Argum., Vitória, v. 12, n. 2, p. 36-43, maio/ago. 2020. | ISSN 2176-9575 
institucionais decisórios como espaços exclusivos dos interesses da classe dominante. Impedindo, por meio de uma série de artifícios econômicos, políticos e culturais, que as demandas populares de cunho reformista possam adentrar a cena política institucional, essas novas democracias se definem pelo seu conteúdo essencial contrarreformista (DEMIER, 2017, p. 33).

No Brasil, então, a recente regressão da política de saúde mental deve ser examinada não somente como "[...] ruptura do pacto democrático e social celebrado com a Constituição de 1988" (DELGADO, 2019, p. 3), mas pela atualização neoconservadora do componente de contrarreforma da nossa democracia.

2 O neoliberalismo no pensamento de Eduardo Mourão Vasconcelos: de elemento das análises de conjuntura para a apreensão de uma tendência estrutural

O mirante de Vasconcelos (2020) - psicólogo e cientista político - para o texto em debate parece estar mais assentado nesta última formação. A partir dos estudos de Wendy Brown, Vasconcelos (2020) concorda com a extensão histórica do projeto neoliberal e seu ataque à esfera do social e à valorização das esferas pessoal e familiar.

\begin{abstract}
Ademais, para os intelectuais e elaboradores de políticas neoliberais, a família não era apenas uma rede de proteção, mas um reservatório de disciplina e uma estrutura de autoridade. Eles buscavam nela um entrave aos excessos democráticos e ao colapso da autoridade que acreditavam ser incitados pelas provisões do Estado social, especialmente aqueles relativas ao bem-estar e ao ensino superior público. Se os indivíduos pudessem voltar a depender da família para tudo, [...] eles também seriam ressubmetidos à autoridade, moralidade e disciplina econômica da família (BROWN, 2019, p. 114).
\end{abstract}

Para um estudo mais sistemático das influências recebidas pelos intelectuais da reforma psiquiátrica e da luta antimanicomial no Brasil, Vasconcelos (2020) é uma das referências a ser consultadas, considerando que sua formação se deu em solo político limitado pela Ditadura Militar, mas aberto à participação de experiências comunitárias militantes que foram um dos embriões do processo da redemocratização no país. A contribuição dele ao processo de constituição da reforma psiquiátrica brasileira mereceria em outro espaço uma recuperação mais sistemática de sua biobibliografia que nos facultasse melhor delineamento à respeito dos conhecimentos acionados para forjar o mirante do autor.

Essa sinalização se deve a como a obra de Vasconcelos (2020) cobre a crítica à psiquiatria, indica os avanços edificados pela saúde mental ao longo dos anos 1990 a 2010 e coteja o neoliberalismo como agenda que condiciona a reforma psiquiátrica brasileira nas últimas três décadas e meia. Conquanto, o que apareceu como um componente relevante nas análises de conjuntura do autor (VASCONCELOS, 2012), vai emergindo como um projeto e um solo histórico fundamental (VASCONCELOS, 2016). Aqui, não se está afirmando que o autor tratasse o neoliberalismo como um fenômeno conjuntural em textos anteriores, mas que essa ofensiva se apresentou de forma central nesse artigo, revisitando alguns dos teóricos seminais reunidos por Brown (2019), como Friedrich Hayek e Milton Friedman, dentre outros. Brown (2019) demonstra que as forças na 
atualidade "[...] requer avaliar a cultura política e a produção subjetiva neoliberais, e não somente as condições econômicas e os racismos persistentes que a geraram" (BROWN, 2019, p. 17).

O desmonte das conquistas da política de saúde mental (AMARANTE; NUNES, 2018; DELGADO, 2019), acelerado a partir do Governo de Michel Temer (2016-2018) e agravada no atual Governo Bolsonaro (2019 até o momento), é consequência das escolhas de políticas de governo associadas à racionalidade de contrarreforma neoliberal que favorece a recomposição das taxas de lucro do capital, erode os direitos dos trabalhadores, demoniza o Estado social e a política, além de atacar a igualdade e de exaltar a liberdade do mercado. Nesta racionalidade, ainda, encontramos a defesa do nacionalismo, de uma moralidade impositiva e sob a amálgama de uma religiosidade cristã e de um ataque à ciência. Em tempos de enfrentamento à uma crise sanitária internacional, esses traços do neoliberalismo são colocados em xeque, ao mesmo tempo em que ampliam os desafios para o enfrentamento da pandemia e dos agravos sociais.

Para Dardot e Lavat (2016, p. 379), estamos diante de uma “[...] nova razão do mundo[...]” expressa em uma “[...] mutação muito mais radical [...]”(DARDOT; LAVAT, 2016, p. 379), que afeta a "[...] dessimbolização da política [...]" e uma "desdemocratização" (DARDOT; LAVAT, 2016, p. 379). "A função do liberalismo no passado foi pôr um limite aos poderes dos reis. A função do liberalismo no futuro será limitar o poder de parlamento submetidos à pressão impaciente das massas incultas" (DARDOT; LAVAT, 2016, p. 50).

Nesse mal estar da democracia burguesa, Demier (2017) chama atenção para a democracia blindada brasileira que nos parece pôr enormes desafios para a saúde mental brasileira. Que brechas, como nomeia Vasconcelos (2020), ou trincheiras, como indica Delgado (2019), então, devem os trabalhadores, usuários e familiares ocuparem para a defesa de um outro lugar social para a loucura?

A democracia liberal brasileira se converte, finalmente, num arranjo político voltado centralmente para a retirada de direitos democráticos. Sem nunca ter gozado de suas virtudes, a democracia brasileira compartilha de todos os males das democracias europeias do tempo presente, as quais, desde os anos 1980, se esmeram em concretizar o histórico projeto liberal de apartar a democracia do demos, blindando as instituições do regime diante da pressão e participação populares. Antes de se efetivar muitos dos direitos previstos em lei, a democracia blindada brasileira já dirige todas as suas armas contra eles, clamando pela supressão daquilo que jamais concretamente existiu, afirmando ser vetusto aquilo que sequer nasceu. Paradoxalmente, o regime democrático constitucional brasileiro faz da sua Constituição, ou melhor, da parte social desta, o seu pior inimigo, e tem nos saudosistas da velha ordem verde-oliva dos atos institucionais alguns dos seus mais fiéis aliados na luta por um futuro democraticamente cinzento. Eles vêm com uma se de anteontem, porque, na verdade, apenas toleraram o ontem. Em sintonia com as democracias blindadas ocidentais, o Brasil começa a se despedir do Estado de Bem Estar Social, com a curiosa particularidade de que ele nunca o vivenciou de verdade. Tudo que não era sólido se desmancha no ar. (DEMIER, 2017, p. 98, grifo do autor).

Argum., Vitória, v. 12, n. 2, p. 36-43, maio/ago. 2020. | ISSN 2176-9575 
Manter a aposta de uma desinstitucionalização na saúde mental, orientada por valores radicalmente democráticos, requer revisitar a processualidade histórica que a conforma o tipo de democracia burguesa e identificar pistas para a luta política.

\section{Encontros e trincheiras na reforma psiquiátrica brasileira: breves notas}

A experiência brasileira de desinstitucionalização tem reconhecimento internacional ao implementar uma política nacional de saúde mental, considerando ser o Brasil um país de nível médio de renda. Segundo Almeida (2019), a nossa trajetória com diversos projetos inovadores atraiu grande interesse internacional, sendo acompanhada em seus avanços e fragilidades. Do ponto de vista do primeiro, o autor destaca o deslocamento do modelo assistencial e o financiamento da atenção hospitalar para a atenção comunitária, como principais indicadores; enquanto que o subfinanciamento foi o problema mais robusto de toda a reforma psiquiátrica brasileira. Em 2015, na avaliação promovida pela Fundação Calouste Gulbenkian em parceria com a Fundação Oswaldo Cruz com título Inovações e desafios em desinstitucionalização e atenção comunitária no Brasil, o documento reconhece os avanços substanciais, mas sinaliza que o processo brasileiro da Reforma está longe de ser considerado plenamente exitoso.

O financiamento insuficiente se inscreve no padrão de política social sob a agenda neoliberal. Não é ocasional nem intermitente. Gestores, trabalhadores, legisladores, operadores do Direito, usuários e familiares, participantes de uma arena ampla e diversa da luta antimanicomial, trabalharam e militaram pelo alargamento da rede territorial e substitutiva de serviços, pelo controle social, pela aprovação da Lei no 10.216 e pela inscrição da loucura nos direitos da sociedade. Conquanto, uma das concessões ao projeto neoliberal merece destaque em certas esferas do Executivo, como a defesa de que a expansão da rede de saúde mental no SUS poderia ocorrer com a ampla terceirização dos seus trabalhadores. Como dito, isso vai ao encontro da agenda neoliberal que avilta os direitos trabalhistas, através de contratos de trabalhos precarizados e com rendimentos cada vez menores, aprofundando o cariz de cobertura universal da saúde pública em detrimento de um efetivo sistema universal, cuja disputa se coloca na ordem do dia com a pandemia do COVID-19. Aqui, está se tratando da concepção de universalidade defendida por organismos internacionais como o Banco Mundial e a Organização Mundial de Saúde que a reduz à "[...] cobertura por serviços básicos, ou por cobertura de seguros de saúde, públicos ou privados, indicando ênfase no subsídio à demanda, em detrimento da construção de sistemas públicos universais" (GIOVANELLA et al., 2018, p. 1764).

Na quadra atual, a política de saúde mental se desenvolve no interior de um SUS desfinanciado, mas se mantém como uma das trincheiras da luta antimanicomial. Reconhecer o substrato neoliberal pode nos facultar fortalecer o vetor político nos encontros intersetoriais do cotidiano de trabalho e nos articular com resistências e lutas do movimento sindical, estudantil, feministas, antiproibicionista às drogas, antirracistas e tantos outros com cariz emancipatório.

Argum., Vitória, v. 12, n. 2, p. 36-43, maio/ago. 2020. | ISSN 2176-9575 


\section{Considerações finais}

Construir o lugar social com aqueles que experimentam a loucura nos desafia a romper generalizações como a dos perfis sociais e as da nosografia psiquiátrica. Vasconcelos (2020) segue nos convidando à educação permanente aliada à militância política, sempre como processo cumulativo.

Seguramente, nenhum sujeito individual ou coletivo domina o caminho para reversão do projeto neoliberal. A luta por direitos sociais, mesmo na ordem burguesa, se torna estratégica para propiciar os meios para a reprodução da vida, condição inclusive para nos manter vivos e nos coletivizarmos. A reforma psiquiátrica brasileira não é mais infante e está tendo a oportunidade de reavaliar os pressupostos tomados de empréstimo das teorias social e política para uma auto crítica radical aos componentes epistemológico, cultural, legal e assistencial.

Esta crise social e sanitária, portanto, ao desvelar a natureza contrarreformista de nossa democracia, faculta oportunidades para intensificar a luta social para uma direção ética e coletiva de ultrapassagem dessa ordem social e não somente de apassivamento ao vislumbre de direitos sociais. Qual será o lugar social para a loucura nos parece seguir como questão da ordem do dia!

\section{Referências}

ALMEIDA, L. M. C. Política de saúde mental no Brasil: o que está em jogo nas mudanças em curso. Cadernos de Saúde Pública. Rio de Janeiro: ENSP, FIOCRUZ, v. 35, n. 11, 2019.

AMARANTE, P.; NUNES, M. de O. A reforma psiquiátrica no SUS e a luta por uma sociedade sem manicômios. Ciência \& Saúde Coletiva. Rio de Janeiro: ABRASCO, v. 23, n. 6, p. 2067-2074, jun. 2018.

ANTUNES, R. Coronavírus: O trabalho sob fogo cruzado (Pandemia Capital). São Paulo: Boitempo, 2020.

ANTUNES, R. O Privilégio da Servidão: o novo proletariado de serviços na era digital. São Paulo: Boitempo, 2018.

BIRMAN, J. A cidadania tresloucada. In: BEZERRA, B.; AMARANTE, P. (Orgs).

Psiquiatria sem hospício: contribuições ao estado da reforma psiquiátrica. Rio de Janeiro: Relume-Dumará; 1992. p. 71-90.

BROWN, W. Nas ruínas do neoliberalismo: a ascensão da política antidemocrática no Ocidente. São Paulo: Filosófica Polítéia, 2019.

DANTAS, André V. Coronavírus, o pedagogo da catástrofe: lições sobre o SUS e a relação entre público e privado. Trabalho, Educação e Saúde, Rio de Janeiro, v. 18, n. 3, 2020. 
DARDOT, Pierre; LAVAL, Christian. A nova razão do mundo: ensaio sobre a sociedade neoliberal. Tradução Mariana Echalar. 1. ed. São Paulo: Boitempo, 2016.

DEMIER, F. Depois do Golpe: a dialética da democracia blindada no Brasil. Rio de Janeiro: Mauad X, 2017.

DELGADO, Pedro Gabriel. Reforma psiquiátrica: estratégias para resistir ao desmonte. Trabalho, Educação e Saúde, Rio de Janeiro, v. 17, n. 2, 2019.

GIOVANELLA, L.; MENDONZA-RUIZ, A.; PILAR, A. de C. A.; ROSA, M. C. da; MARTINS, G. B.; SANTOS, I. S.; SILVA, D. B.; VIEIRA, J. M. de L.; CASTRO, V. C. G. de; SILVA, P. O da; MACHADO, C. V. Sistema universal de saúde e cobertura universal: desvendando pressupostos e estratégias. Ciência \& Saúde Coletiva, Rio de Janeiro: ABRASCO, v. 23, n. 6, p. 1763-1776, jun. 2018.

ORGANIZAÇÃO INTERNACIONAL DO TRABALHO. Como a COVID-19 afetará o mundo do trabalho? Brasília (DF), 3 abr. 2020. Disponível em: https://www.ilo.org/brasilia/noticias/WCMS_740753/lang--pt/index.htm. Acesso em: 15 abr. 2020.

ROTELLI, F.; LEONARDIS, O.; MAURI, D.. Desinstitucionalização. São Paulo: Hucitec; 1990.

VASCONCELOS, Eduardo Mourão. A gravidade do neoliberalismo radical pós 2008 e nossas estratégias de resistência. Argumentum, Vitória, v. 12, n. 2, 2020.

DOI: http://10.18315/argumentum.v12i2.30483.

VASCONCELOS, E. M. Reforma psiquiátrica, tempos sombrios e resistência: diálogos com o marxismo e o serviço social. São Paulo: Tempo Social, 2016.

VASCONCELOS, E. M. Cenário econômico, social e psicossocial no Brasil recente, e a crescente difusão do crack: balanço e perspectivas de ação. O Social em Questão, Rio de Janeiro: Departamento de Serviço Social, PUC-RIO, ano 15, n. 28, p. 149-186, 2012.

\section{Rita CAVALCANTE}

Assistente Social. Doutora em Serviço Social pela Universidade Federal do Rio de Janeiro (UFRJ).

Professora Associada da Escola de Serviço Social da Universidade Federal do Rio de Janeiro (UFRJ).

Argum., Vitória, v. 12, n. 2, p. 36-43, maio/ago. 2020. | ISSN 2176-9575 